\title{
Age-related differences of intraischemic gap junction uncoupling in hearts during ischemia
}

\author{
Sabrina Lueck, MD, ${ }^{\mathrm{a}}$ Achilles Delis, MD, ${ }^{\mathrm{b}}$ Thomas Minor, $\mathrm{MD},{ }^{\mathrm{c}}$ Claus Juergen Preusse, $\mathrm{MD},{ }^{\mathrm{d}}$ and \\ Michael Schaefer, $\mathrm{PhD}^{\mathrm{e}}$
}

\begin{abstract}
Objective: Myocardial ischemia leads to energetic, morphologic, metabolic, and functional alterations. To evaluate differences in ischemia tolerance between neonatal and adult hearts, we investigated gap junction uncoupling (GJU) and its correlation to myocardial intracellular edema formation during normothermic ischemia.
\end{abstract}

Methods: Hearts of landrace piglets (neonates, $7.4 \pm 1.9$ days of age, body weight $2.9 \pm 0.5 \mathrm{~kg}, \mathrm{n}=5$ and adults, $84 \pm 9$ days of age, body weight $30.5 \pm 3.9 \mathrm{~kg}$, $\mathrm{n}=5$ ) were investigated. After we harvested the hearts, the bioelectrical impedance spectra were measured continuously during normothermic global ischemia $\left(35^{\circ} \mathrm{C}\right)$. Spectra of the dielectric permittivity, $\varepsilon^{\prime}$ (frequency), and conductivity, $\sigma$ (frequency), were calculated from the impedance measurements, and GJU was identified in the sigmoidal time course of $\varepsilon^{\prime}(13 \mathrm{kHz})$. The extracellular volume was estimated by the ratio $\sigma(100 \mathrm{~Hz}) / \sigma(1 \mathrm{MHz})$. Dielectric data were correlated with electron-microscopical images.

Results: Intraischemic GJU was observed in neonates after $54 \pm 9$ minutes of ischemia and thus significantly earlier than in adults $(90 \pm 7$ minutes, $P<.05)$. A more than $20 \%$ increase of intercalated water was found in tissue samples of neonates after $20 \pm 2$ minutes, in contrast to adults after $137 \pm 8$ minutes $(P<.05)$.

Conclusions: Intraischemic formation of edema and earlier GJU indicate faster intraischemic changes in neonates compared with adults. Intraischemic GJU and determination of intracellular water shifts are an experimental approach to establish the period of life-threatening damage. Because both parameters are linked and occur significantly earlier in neonates, they distinctly demonstrate the lower ischemia tolerance of neonatal hearts as both events interact. ( $\mathrm{J}$ Thorac Cardiovasc Surg 2016;152:729-36)

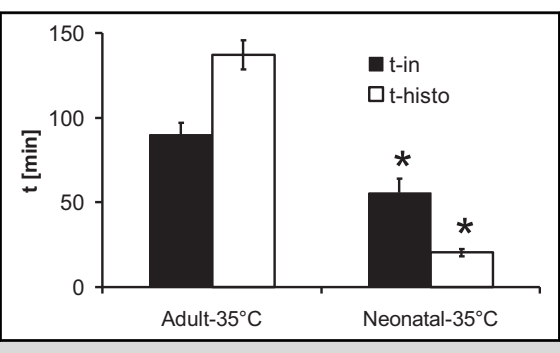

Time of inflexion (t-in) obtained from the intraischemic time course of the dielectric permittivity, $\varepsilon^{\prime}$, at $13 \mathrm{kHz}$ compared with the time $t$-histo (ie, time concerning histologic alterations), when the intercalated water area found by digital image processing reached $20 \%$ during ischemia (mean \pm standard error of the mean, *significant compared with the corresponding parameter in the adult heart group, $P \leq .05)$

\section{Central Message}

In neonatal hearts, significantly faster edema formation and earlier gap junction uncoupling during ischemia were measured, indicating greater sensitivity compared with adult hearts.

\section{Perspective}

With the purpose to correlate edema formation in congenital heart surgery to intraischemic gap junction uncoupling, we investigated adult and neonatal piglet hearts under standardized conditions of normothermic ischemia. To our knowledge, this is the first study of intraischemic gap junction regulation in neonatal hearts ever assessed by electrical impedance spectroscopy.

See Editorial page 655

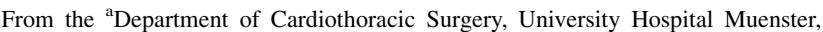
Muenster; Departments of ${ }^{\mathrm{b}}$ Anesthesiology and ${ }^{\mathrm{d}}$ Cardiac Surgery, University Hospital Bonn, Bonn; ${ }^{\mathrm{c}}$ Department of Surgical Research, University Hospital Essen, Essen; and ${ }^{\mathrm{e}}$ Section Surgical Research, University Hospital Heidelberg, Heidelberg, Germany.

This study was financially supported by the German Heart Foundation.

Received for publication Nov 18, 2015; revisions received March 18, 2016; accepted for publication April 14, 2016; available ahead of print May 25, 2016.

Address for reprints: Sabrina Lueck, MD, Division of Cardiac Surgery, Department of Cardiothoracic Surgery, University Hospital of Muenster, Germany, AlbertSchweitzer-Campus 1, 48149 Muenster, Germany (E-mail: sabrina.lueck@ ukmuenster.de).

$0022-5223 / \$ 36.00$

Copyright (C) 2016 by The American Association for Thoracic Surgery

http://dx.doi.org/10.1016/j.jtcvs.2016.04.069
}

Despite the immense progress achieved in the surgical treatment of congenital heart malformations within the last 20 years, extensively edematous hearts frequently are seen in congenital heart surgery. Surgical procedures cause prolonged ischemia and thus provoke the formation of

Scanning this QR code will take you a video for the article.

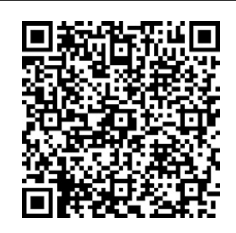




$$
\begin{aligned}
& \text { Abbreviations and Acronyms } \\
& \begin{aligned}
\text { ATP } & =\text { adenosine triphosphate } \\
\text { bw } & =\text { body weight } \\
\text { DSC } & =\text { delayed sternal closure } \\
\varepsilon^{\prime} & =\text { permittivity } \\
\text { ECSI } & =\text { extracellular space index } \\
\text { GJU } & =\text { gap junction uncoupling } \\
t \text {-histo } & =\text { time concerning histological alterations } \\
t \text {-in } & =\text { time up to the point of inflexion, in } \varepsilon^{\prime}(\mathrm{t})
\end{aligned}
\end{aligned}
$$

edema, ${ }^{1}$ sometimes resulting in delayed sternal closure (DSC). The incidence of DSC varies greatly and depends on the congenital heart malformation and the surgical procedure, for instance, Stage 1 palliation for left heart syndrome. ${ }^{2,3}$ Statistically significant risk factors for DSC are pathologies of myocardial malformations, duration of cardiopulmonary bypass and cross clamp times, as well as the age of the neonates. ${ }^{4,5}$ Undoubtedly, extended cardiopulmonary bypass time, in particular, carries the risk of total tissue water accumulation, but the significance of ischemia-induced myocardial intracellular edema formation must not be underestimated.

DSC is considered an effective therapeutic option for neonates/infants at risk for hemodynamic, respiratory, or hemostatic instability early after congenital heart surgery. Frequently, myocardial edema delays sternal closure. To reduce such extensive intraoperative edema, one needs to evaluate mechanisms that may be involved in this pathophysiologic process (eg, cardioplegic strategies, temperature management).

Under ischemic conditions, anaerobic glycolysis becomes the major pathway of energy support. Both lactate and hydrogen ions are produced as end products. ${ }^{6}$ A balanced $\mathrm{pH}$ value is necessary to maintain cellular functions and indirectly stabilizes intra- and extracellular water distribution caused by ion homeostasis in the intraand extracellular space. Intraischemic lactate production in neonates is remarkably greater than in adults, whereas intracellular proton buffer capacity is significantly lower. ${ }^{7,8}$ Consequently, lower ischemia tolerance in neonates can be explained by lower buffering reserve and by more intensive accumulation of glycolytic metabolites, leading to an early water shift from the extra- to the intracellular space. The result of this pathophysiologic process is a progressive myocardial intracellular edema that occurs during ischemia and during the first hours postoperatively.

Aside from the formation of edema, long-lasting ischemia in myocardial tissue induces gap junction uncoupling (GJU) and damage to cell membranes. ${ }^{9}$ Gap junctions can be uncoupled by several substance ${ }^{10,11}$ and potential intraischemic triggers, such as a decrease in adenosine triphosphate (ATP) content, increase in intracellular calcium concentration, or cellular acidosis. Therefore, GJU depends on the progressive ischemia that occurs during transition from life to death. ${ }^{12}$ Consequently, the formation of edema and GJU are important parameters that indicate heart tissue damage during ischemia.

The intent of our study was to investigate the lower ischemia tolerance of neonatal hearts as compared with adult hearts, reflected in the formation of edema and GJU. Therefore, we examined adult and neonatal piglet hearts under standardized conditions of normothermic ischemia and assessed the formation of edema by the analysis of histologic images and measured GJU by electrical impedance spectroscopy. To our knowledge, this is the first study of intraischemic gap junction regulation in neonatal hearts ever assessed by electrical impedance spectroscopy.

\section{MATERIALS AND METHODS Experimental Procedure}

The experiments were carried out in landrace piglets that received humane care according to the Guide for the Care and Use of Laboratory Animals (National Institutes of Health pub. 86-23, revised 1985). The neonatal piglets (neonates) had a mean body weight (bw) of $2.9 \pm 0.5 \mathrm{~kg}$ and were between 6 and 10 days of age $(\mathrm{n}=5$, $7.4 \pm 1.9$ days). The adult pigs (adults) had a mean weight of $30.5 \pm 3.9 \mathrm{~kg}$, and their median age was 3 months $(\mathrm{n}=5$, $84 \pm 9$ days). All pigs were intubated and ventilated after premedication with midazolam $(0.5 \mathrm{mg} / \mathrm{kg}$ bw) and ketamine $(15-20 \mathrm{mg} / \mathrm{kg} \mathrm{bw})$. Anesthesia was sustained with midazolam $(0.5 \mathrm{mg} / \mathrm{kg} \mathrm{bw})$, fentanyl $(0.001 \mathrm{mg} / \mathrm{kg} \mathrm{bw})$, pancuronium $(0.1 \mathrm{mg} / \mathrm{kg} \mathrm{bw})$, and isoflurane. Fentanyl was used in our experiments because it is administered routinely for analgesia in small children. It attenuates myocardial injury caused by high-dose adrenaline ${ }^{13}$ and is known to provoke preconditioning. Neonatal and adult hearts, however, both benefit from the positive effects of fentanyl, so that the comparison of both groups is less affected.

After median sternotomy, both caval veins were clamped as well as the aortic and pulmonary artery, resulting in global ischemia. Afterwards, the hearts were directly harvested for our ex vivo experimental setup and immediately stored in an incubator at a humidity of $30 \%$ (according to Murphy ${ }^{14}$ ) and constant temperature of $35^{\circ} \mathrm{C}$ (Video 1). Normothermia was deliberately chosen to induce high ischemic myocardial stress and to provoke early myocardial injury.

\section{Measurement of GJU and Monitoring of Changes in the Extracellular Volume}

Electrical impedance spectroscopy method was used for the measurement of intraischemic GJU and to estimate the extracellular volume. The impedance measurements were performed by the use of electrodes in constant contact with the heart tissue surface. A probe consisting of 4 parallel electrodes was placed on the epicardial layer of the left ventricle parallel to the anterior interventricular branch of the left coronary artery. The outer 2 electrodes injected current to the tissue and the inner 2 sensed the voltage. With a Solartron 1260 impedance analyzer (Solartron Analytical, Leicester, United Kingdom) controlled by ImpDAQ V1.03 iba e. V. software (ImpDAQ, Bad Heiligenstadt, Germany), the complex electrical 


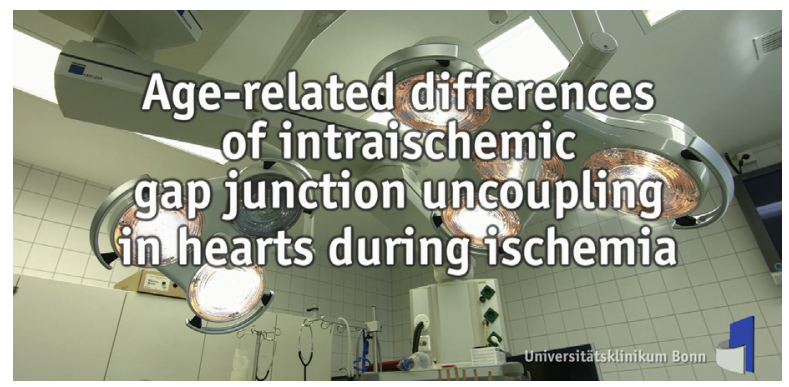

VIDEO 1. Technical aspects of the experiments are shown and how they are performed in the laboratory is explained. Additional information about bioimpedance measurements is provided. Video available at http://www. jtcvsonline.org/article/S0022-5223(16)30277-X/addons.

impedance spectra of the hearts were measured continuously between $100 \mathrm{~Hz}$ and $1 \mathrm{MHz}$ during normothermic ischemia.

The complex dielectric permittivity spectrum in equation (1) is as follows:

$$
\varepsilon(\omega)=\varepsilon^{\prime}(\omega)-i \frac{\sigma(\omega)}{\varepsilon_{0} \omega}, \quad \varepsilon_{0}=8.85 \frac{A s}{V m}, \omega=2 \pi f
$$

(imaginary unit $i=\sqrt{-1}, f=$ frequency) was calculated from the complex impedance measurements $Z(\omega)=Z^{\prime}(\omega)+i Z^{\prime \prime}(\omega)$ using equation (2),

$$
\varepsilon(\omega)=\frac{1}{i \omega Z(\omega)}-\frac{C_{c o n}}{C_{0}}
$$

where $C_{0}=$ capacity of the electrodes and $C_{c o n}=$ capacity of the connecting network between electrodes and impedance analyzer.

GJU during ischemia was monitored by means of the time course of dielectric permittivity $\left(\varepsilon^{\prime}\right)$ at $13 \mathrm{kHz}$. We abstained from individual validation experiments because basic validation studies concerning the correlation of $\varepsilon^{\prime}$ at $13 \mathrm{kHz}$ and intraischemic GJU in myocardial tissue have already been performed by Schaefer et $\mathrm{al}^{10}$ and Knapp et al. ${ }^{15} \mathrm{GJU}$ during ischemia induced a sigmoidal increase of $\varepsilon^{\prime}$ at $13 \mathrm{kHz}$, as illustrated in the schematic diagram of a stylized time curve (Figure 1). For comparison, the time up to the point of inflexion in $\varepsilon^{\prime}(\mathrm{t})(t-i n)$ in the sigmoidal time response of the dielectric permittivity at $13 \mathrm{kHz}$ was determined, indicating the time up to GJU during ischemia.

According to the suggestions by Gersing ${ }^{16}$ and Mellert et al, ${ }^{17}$ electrical impedance spectroscopy can be used for the estimation of extracellular volume. With the assumption of a current exclusively running through the extracellular space at low frequencies and a current distribution in the intra- and extracellular space at high frequencies, we estimated the extracellular volume from the dielectric data by the extracellular space index (ECSI) in equation (3), which was defined as the quotient of the tissue conductivity at the lowest and the highest available frequency,

$$
E S C I=\frac{\sigma_{100 H z}}{\sigma_{1 M H z}}
$$

where $\sigma=$ measured tissue conductivity.

\section{Tissue Histology and Quantification of Intercalated Water}

During ischemia, multiple specimens were taken from the apex of all hearts for electron microscopic analyses at predefined time points (adults: onset of ischemia, after 60, 120, and 180 minutes; neonates: $0,30,60$, and 120 minutes of ischemia). Because our first observational experiments on

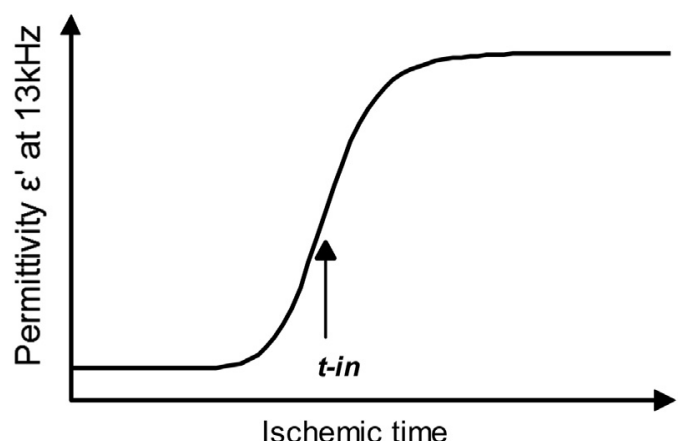

FIGURE 1. Schematic diagram of a stylized sigmoidal time course of the dielectric permittivity, $\varepsilon^{\prime}$, at $13 \mathrm{kHz}$ during myocardial ischemia. The time point $t$-in represents the breakpoint of the curve. $\varepsilon^{\prime}$, Permittivity; $t$-in, time up to the point of inflexion, in $\varepsilon^{\prime}(\mathrm{t})$.

neonatal and adult hearts had shown earlier changes of the bioimpedance parameters in neonates, tissue samples for histologic analyses were taken at shorter time intervals in this group. Glutaraldehyde was used as fixative to cross-link molecules with each other. Afterwards, tissue was dehydrated in alcohol. After that, the embedded specimens were cut into thin sections by a diamond knife of an ultramicrotome for further studies with the electron microscope.

The grayscale value images obtained by electron microscopy had dark gray areas showing the contractile apparatus of the myocardium. Cellular compartments, including areas of intercalating water, appeared in light gray. We analyzed the electron microscopy images by means of the customized computer software HISTO.EXE (University Hospital Heidelberg, Heidelberg, Germany), counted the light gray pixels in each image, and expressed them as a percentage of the whole image. For comparison, time t-histo (ie, time concerning histological alterations) was determined when the percentage of the light gray area reached $20 \%$ during ischemia. The planimetric analysis of electron-microscopical images was used because other methods such as continuous dehydration and weighing or magnetic resonance imaging were inappropriate for our research question. The method of drying and weighing is not suitable to differentiate between intra- and extracellular water (that should be constant in an isolated organ), and analysis of edema at the cellular level by magnetic resonance imaging is impossible because of the restricted spatial resolution.

\section{Statistics}

Results are quoted as mean \pm standard error of the mean. Statistical differences between data sets were calculated by Wilcoxon rank sum test. The null hypothesis was rejected if $P \leq .05$.

\section{RESULTS}

The time courses of the dielectric permittivity $\varepsilon^{\prime}$ at $13 \mathrm{kHz}$ during ischemia showed a characteristic sigmoidal increase in both neonates and adults followed by a slight decrease during ongoing ischemia (Figure 2, A). In comparison with adults, this characteristic increase was observed earlier during ischemia in neonates. The tissue conductivity at $100 \mathrm{~Hz}, 13 \mathrm{kHz}$, and at $1 \mathrm{MHz}$ in both groups (Figure 2, $B$ and $C$ ) showed a characteristic sigmoidal decrease with progressive ischemia, but the amount of the decrease was clearly smaller at $1 \mathrm{MHz}$ compared with the other 2 . 

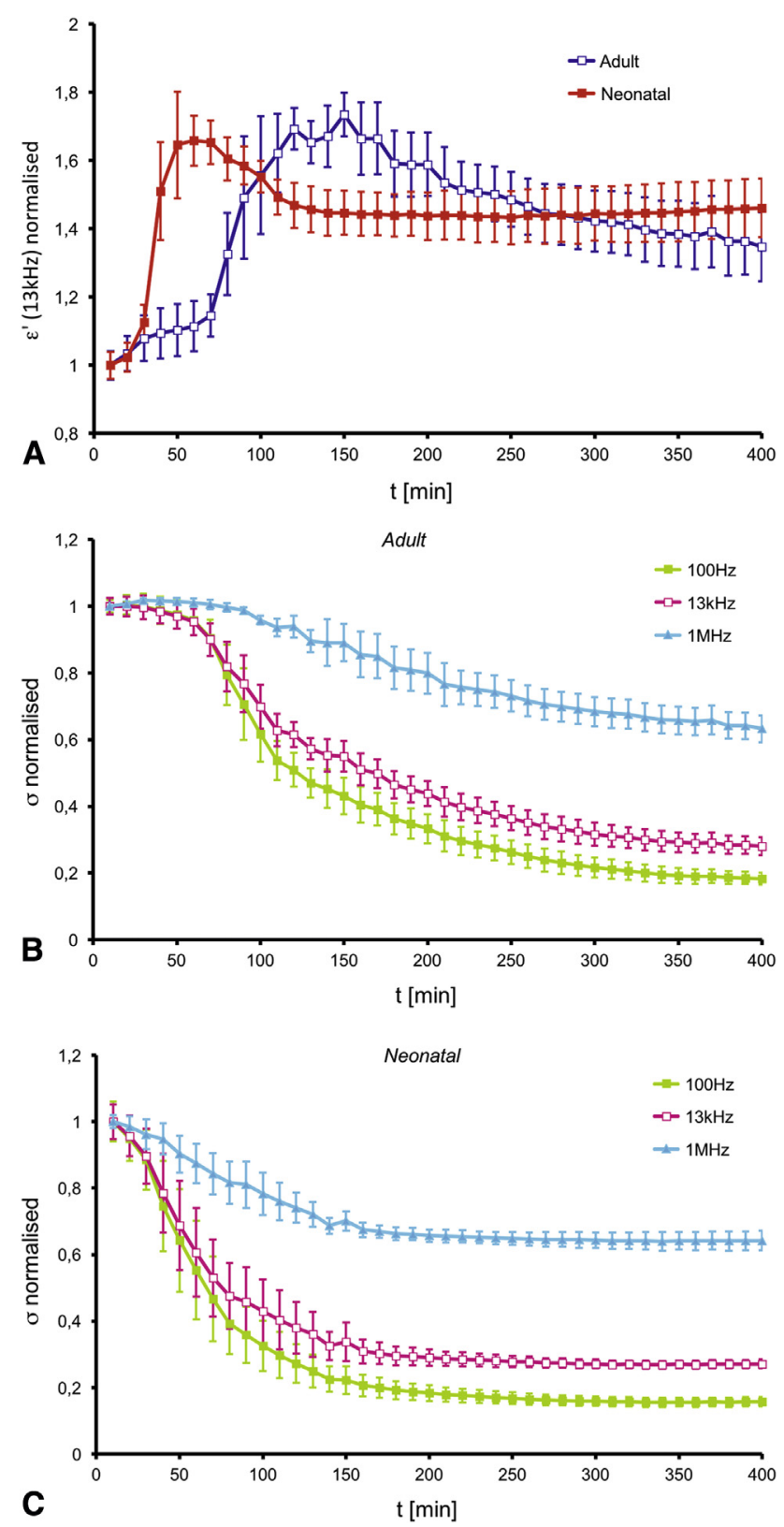

FIGURE 2. Dielectric permittivity $\varepsilon^{\prime}$ measured at $13 \mathrm{kHz}$ for A, neonatal and adult pig hearts and the tissue conductivity at $100 \mathrm{~Hz}, 13 \mathrm{kHz}$, and $1 \mathrm{MHz}$ for $\mathrm{B}$, adult and $\mathrm{C}$, neonatal hearts during ischemia at $35^{\circ} \mathrm{C}$. The data were normalized to the first measured value (mean \pm standard error of the mean, $\mathrm{n}=5$ in each group). $\varepsilon^{\prime}$, Permittivity; ECSI, extracellular space index.

The ECSI showed a slight decrease at the beginning of ischemia followed by a steep decrease and a period of more moderate decline to values below 0.2 (Figure 3). The period of steep decrease in ECSI occurred earlier in neonates compared with adults, but there was convergence of both curves after 400 minutes of ischemia.

During ischemia at $35^{\circ} \mathrm{C}$, distinct changes could be seen in tissue histology, as demonstrated by the representative

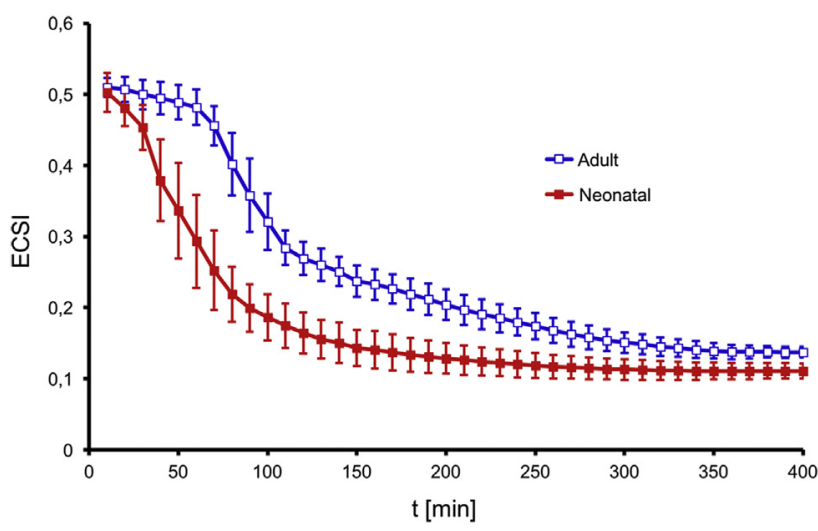

FIGURE 3. The extracellular space index calculated from equation (1) for neonatal and adult pig hearts during ischemia at $35^{\circ} \mathrm{C}$ (mean \pm standard error of the mean, $\mathrm{n}=5$ in each group). ECSI, Extracellular space index.

electron microscopy images at 0,60 , and 120 minutes for adults (Figure 4, A-C) and neonates (Figure 4, D-F). At the onset of ischemia, in adult hearts the tissue appeared predominantly dark gray and the nondisturbed striation of the contractile apparatus could be visualized (Figure 4, A). Already after 60 minutes, but definitively after $120 \mathrm{mi}-$ nutes of ischemia, some areas in light gray appeared within the contractile apparatus of the cells, indicating an accumulation of intracellular water (Figure 4, $B$ and $C$ ). At the beginning of ischemia, only few areas of the neonatal myocardial tissue appeared in light gray, and the contractile apparatus seemed to be unaltered at this stage (Figure 4, $A$ ). At 1 hour later, pronounced alterations of the myocardial tissue could be visualized (Figure 4, E), and large light gray areas could be detected in the electron microscopy images. Furthermore, a disrupted striation of the contractile apparatus could be demonstrated another 60 minutes later (Figure 4, F).

Ischemia-dependent alterations of adult and neonatal myocardium could be analyzed by the quantification of the light gray areas in the electron microscopy images (Figure 4). Initially, the percentage of light gray areas was only slightly greater in neonates than in adults; however, after 30 minutes of ischemia, the interferences detected in neonatal hearts were much more extensive compared with the adult hearts.

The relation between the time course of tissue structure alterations and changes in the dielectric properties were demonstrated by comparing of the time point t-histo, the time point when fraction of the light gray areas reached $20 \%$ during ischemia, and the time point $t$-in, the time of inflexion found in the sigmoidal time course of the dielectric permittivity $\varepsilon^{\prime}$ at $13 \mathrm{kHz}$ (Figure 5). In adult hearts, $t$-in was smaller than $t$-histo, but the chronological order was reversed in neonates. In comparison with the respective parameter of adult hearts, $t$-in and $t$-histo of neonatal hearts were significantly smaller. 

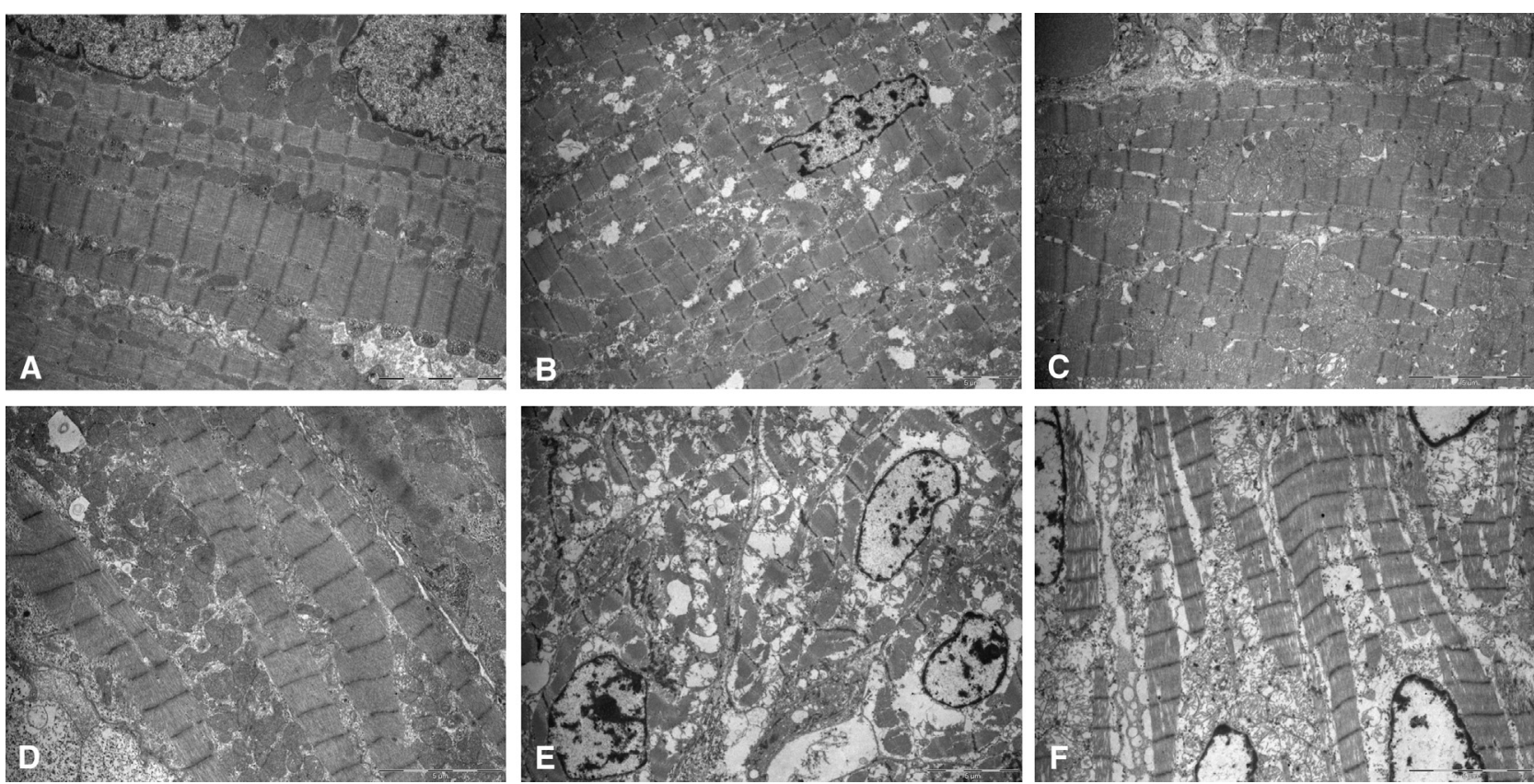

FIGURE 4. Electron microscopy images of adult (A, $0 \mathrm{~min}$; B, $60 \mathrm{~min}$; C, $120 \mathrm{~min}$ ) and neonatal myocardium (D, $0 \mathrm{~min} ; \mathrm{E}, 60 \mathrm{~min}$; F, $120 \mathrm{~min})$ during ischemia at $35^{\circ} \mathrm{C}$. Scale $=5 \mu \mathrm{m}$.

\section{DISCUSSION}

There is no doubt that myocardial ischemia leads to edema formation intra- as well as postischemically. In adults, such an edema formation plays a minor role, but in neonates it has a profound impact on the peri- and postoperative treatment (eg, DSC). Previous studies concerning the formation of edema primarily were based on morphologic analyses. Bioelectrical impedance spectroscopy, which was used by different working groups, ${ }^{10,18}$ is a further method to analyze the water shift between the extra- and intracellular space during and after ischemia; however, this method was only used in adult canine hearts until now. To our knowledge, no comparable investigations of

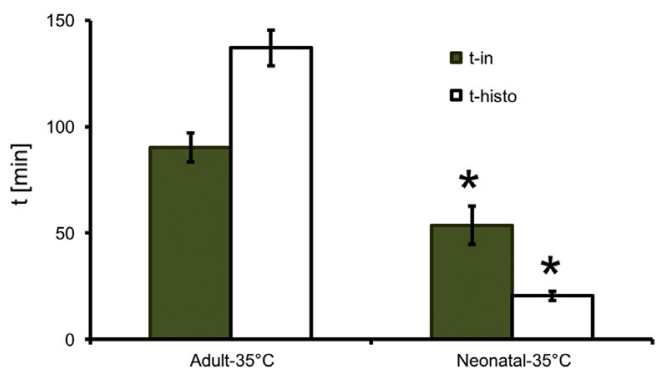

FIGURE 5. Time of inflexion ( $t$-in) obtained from the intraischemic time course of the dielectric permittivity $\varepsilon^{\prime}$ at $13 \mathrm{kHz}$ compared with the time t-histo, when the intercalated water area found by digital image processing reached $20 \%$ during ischemia (mean \pm standard error of the mean, *Significant in comparison with the corresponding parameter in the adult heart group, $P \leq .05$ ). t-histo, Time concerning histological alterations. the ischemic neonatal myocardium have been conducted before.

This study was performed mainly to determine the underlying basic mechanisms of intra- and postoperative edema formation but further impacts of intraoperative modulations (decreased temperature, cardioplegia) must still be analyzed.

The estimation of edema formation by the ECSI is based on the hypothesis that, in biological tissues, alternating current only flows through the extracellular space at low frequencies, ${ }^{19}$ whereas at high frequencies, the current runs through the extra- as well as through the intracellular space. Gersing et $\mathrm{al}^{12}$ demonstrated that this hypothesis was proven valid in porcine liver at $0.1 \mathrm{~Hz}$. According to this assumption, the ratio $R$-high/R-low correlates well with changes of the extracellular volume. To investigate the ESCI of heart tissue, different suggestions for the appropriate frequencies in the impedance spectrum have been used. Gersing ${ }^{16}$ preferred a quotient of $4 \mathrm{MHz}$ and $200 \mathrm{~Hz}$, but Mellert et $\mathrm{al}^{17}$ used $1 \mathrm{MHz}$ and $1 \mathrm{kHz}$. In our experiments, we took the highest and the lowest available frequency and calculated the conductivity ratio with $100 \mathrm{~Hz}$ and $1 \mathrm{MHz}$. To check whether the frequencies fulfilled the purpose of an exclusive extracellular current injection at $100 \mathrm{~Hz}$ and a parallel current via the intraand extracellular space at $1 \mathrm{MHz}$, we compared the time courses of these 2 frequencies with the time course at $13 \mathrm{kHz}$ (Figure 2, $B$ and $C$ ).

At $1 \mathrm{MHz}$, the time course was different from the other frequency curves, but at $100 \mathrm{~Hz}$ the time course was almost 


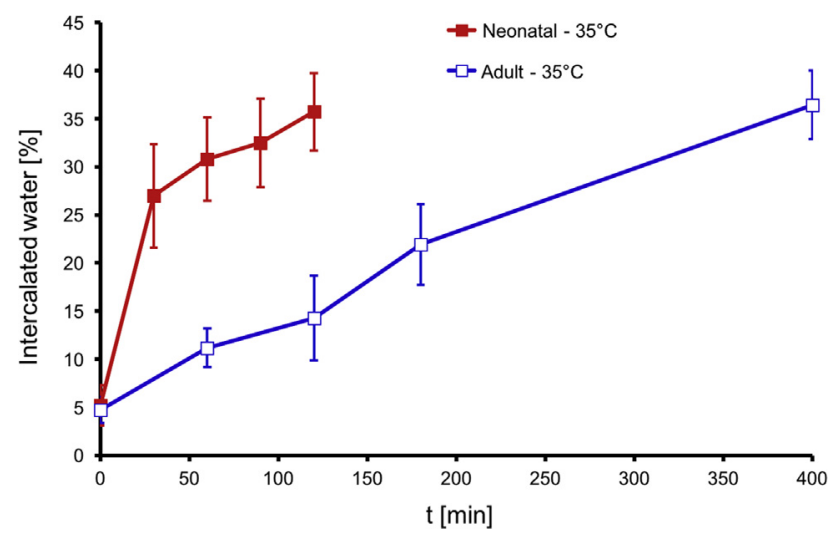

FIGURE 6. Percentage of intercalated water determined from electron microscopy images by digital image processing. Data are shown for neonates and adults during ischemia at $35^{\circ} \mathrm{C}$ (mean \pm standard error of the mean).

identical to the time course at $13 \mathrm{kHz}$. Therefore, we concluded that the current (although only partially) crossed membranes and the intracellular space, too. Consequently, the assumption of an exclusively extracellular current flow could not be supported by our experiments. The current passing the intracellular space indicated that the ECSI was influenced by GJU. When comparing the time courses of the ECSI for neonates and adults (Figure 3) with the appropriate time courses of the dielectric permittivity $\varepsilon^{\prime}$ at $13 \mathrm{kHz}$ (Figure 2, A), we analyzed a steep decrease in the ECSI curves during ischemia while the sigmoidal curve of $\varepsilon^{\prime}$ at $13 \mathrm{kHz}$ increased simultaneously.

What is the impact of reperfusion on the edema formation? In former unpublished experiments on adult canine hearts that were primarily kept ischemic and then reperfused, bioimpedance measurements were performed during and after ischemia. ECSI decreased during ischemia and postischemically it reincreased within minutes. The determination of an intra- and/or extracellular water gain during reperfusion is rather difficult, because the formation of edema also is influenced by heart rate, because durations of systole and diastole influence the extent of myocardial edema.

In our study the decrease of the ECSI was compared with histologic findings (Figures 3 and 6). The fraction of the light gray areas as an estimator for the intercalation of water increased during ischemia. Already after $30 \mathrm{mi}-$ nutes, distinctive changes could be identified in neonates, indicating that even short ischemic periods lead to a visible injury of the immature myocardium. The morphologic changes, however, did not occur as fast as the alterations of the ECSI. Hence, we concluded that the estimated edema formation was also affected by intraischemic GJU.

To identify ischemia-related GJU in the dielectric data, we accessed results of Schaefer et al, ${ }^{10}$ who described a characteristic sigmoidal increase in the time course of the dielectric permittivity $\varepsilon^{\prime}$ at $13 \mathrm{kHz}$. This characteristic sigmoidal increase also could be provoked immediately by the addition of the gap junction blocker heptanol to the cardioplegic solution. In another approach, Knapp et al $^{15}$ measured the spread of dye through open gap junctions parallel to the dielectric data acquisition in the same heart and demonstrated that the dye spread stopped when the dielectric permittivity $\varepsilon^{\prime}$ at $13 \mathrm{kHz}$ entered the upper plateau in its intraischemic time course. On the basis of these investigations, we identified intraischemic GJU in our experiments when the dielectric permittivity $\varepsilon^{\prime}$ at $13 \mathrm{kHz}$ showed its characteristic sigmoidal increase during ischemia.

In neonates, both the time $t$-in up to GJU (assessed by dielectric data) and the time t-histo (assessed by the analysis of histological images) indicated rapid edema formation in myocardial tissue (Figure 5). Both parameters occurred significantly earlier in neonates than in adults. Therefore, we conclude that the ischemia tolerance of the neonatal heart is much lower than the one of adults. Furthermore, in adults $t$-in was much smaller than t-histo, whereas both variables emerged inversely in neonates. Thus, intraischemic regulation of GJU and edema formation differed between adults and neonates.

Disturbances in the ion homeostasis result in edema formation of myocardial tissue. Potential trigger candidates for intraischemic GJU are a decrease in intracellular $\mathrm{pH}$, a decrease in ATP, and an increase in intracellular $\mathrm{Ca}^{2+}$-concentration. ${ }^{11}$ During ischemia, decreases in ATP and in $\mathrm{pH}$ are entirely attributable to anaerobic glycolysis. ${ }^{20}$ Because the decrease in ATP does not differ significantly among neonates and adults, it is unlikely that ATP has a major impact on GJU. Contrary to ATP decrease, lactate production differs significantly between neonates and adults. ${ }^{7,21,22}$ Neonatal myocardium produces much more lactate at the same ischemic stress. Greater lactate production combined with lower intracellular buffer capacity of neonatal hearts lead to a faster decrease of intracellular $\mathrm{pH}$ triggering the GJU. ${ }^{23}$ From patch clamp studies it is known that GJU is induced when the intracellular $\mathrm{pH}$ decreases below 6.5. ${ }^{11}$ This distinct $\mathrm{pH}$ decrease is counteracted by the $\mathrm{Na}^{+} / \mathrm{H}^{+}$exchanger, ${ }^{24,25}$ resulting in increasing intracellular $\mathrm{Na}^{+}$content. Consequently, for osmotic reasons water shifts towards the intracellular space. ${ }^{26}$ This pathophysiologic mechanism might explain the earlier edema formation in ischemic neonatal hearts (Figure 6).

As mentioned previously, the increase of intracellular $\mathrm{Ca}^{2+}$-concentration also triggers intraischemic gap junction regulation. The opening of potential-dependent $\mathrm{Ca}^{2+}$-channels is indirectly affected by the reduced, ischemia-related activity of $\mathrm{Na}^{+} / \mathrm{K}^{+}$-ATPase. The activity of $\mathrm{Na}^{+} / \mathrm{K}^{+}$- 
ATPase is attributable to the increase of intracellular proton concentration. ${ }^{20}$ Because the myocardial cell is depolarized during ischemia, the $\mathrm{Ca}^{2+}$ channels open because they are potential dependent. ${ }^{27}$ The observation of high lactate production, fast decrease of intracellular $\mathrm{pH}$, and $\mathrm{Ca}^{2+}$-accumulation might explain the different rates of GJU in neonates and adults. This hypothesis is substantiated by our experimental results. Our measurements show earlier occurrence of the characteristic changes of dielectric permittivity and faster edema formation in ischemic neonatal hearts.

What are the clinical implications of our experiments? Although it is premature to draw therapeutic conclusions, we could demonstrate that bioelectric impedance measurements are valuable tools to continuously and atraumatically analyze GJU and the formation of edema during ischemia. In contrast to these impedance measurements, histologic or ultrastructural investigations are of inferior value, because they only reflect the morphologic situation at a given moment.

The significantly earlier onset of GJU and concurrent the formation of edema in neonates may explain the far greater incidence of DSC in congenital heart surgery after long-lasting cardiac operations. At this time we cannot distinguish the influence of tissue water gain caused by extracorporeal circulation from that of ischemia-induced myocardial alterations. However, we could show that neonatal hearts are more susceptible to edema formation. Both the formation of edema and GJU are important parameters for the assessment of intraischemic heart damage, for instance, leading to impaired postischemic/postoperative left ventricular function and morphologic alterations. Gap junctional communications and thus cell-cell interactions are altered by preconditioning ${ }^{28}$ and closed gap junctions prevent hypercontracture during reperfusion. ${ }^{29,30}$ As a consequence, intraischemic GJU represents a valuable predictor of critical transition from life to death at normothermia. ${ }^{18,31}$ The intraischemic GJU based on our bioimpedance measurements might be a tool to develop and evaluate new cardioplegic methods targeting the specific manipulation of electrical cell coupling via gap junctions and possibly minimize an intraoperative edema formation.

\section{Limitations}

There are many ischemia/reperfusion studies about neonatal and adults hearts but the results are controversial depending on different animal species. ${ }^{32}$ The porcine model was chosen on purpose because these hearts are similar to human hearts concerning size, structure, and function. ${ }^{33}$

Our study provides information about intraischemic GJU in relation to edema formation but the relevance of changes in both parameters on the quality of postischemic reperfusion was not investigated.
Normothermic ischemia was deliberately chosen for our model to provoke extensive ischemia-induced alterations although in clinical practice most pediatric cardiac surgical cases are usually performed under hypothermia. With regard to further experiments under different conditions (hypothermia, cardioplegia), we extended ischemia up to 24 hours and did not only focus on intraoperative x-clamp periods.

Our data underline the importance of maintaining an aerobic state and keeping the intraoperative ischemic time as short as possible, although we acknowledge that the majority of surgical procedures of congenital malformations can only be performed on an arrested heart. The extent to which GJU and edema formation are influenced by any kind of cardioplegia is unpredictable at the moment, but our experimental results point in an adverse direction. The applied data is helpful for further analyses, that is, to evaluate different cardioplegic methods and/or the use of gap junction blockers and uncoupling inhibitors to minimize an intraoperative edema formation.

\section{CONCLUSIONS}

In neonatal hearts, significantly faster formation of edema and earlier GJU during ischemia at normothermia was measured in comparison with adult hearts, indicating the greater sensitivity of neonatal hearts to ischemia. The noninvasive method of impedance spectroscopy allows continuous monitoring of age-related parameters of GJU during ischemia. This might help to understand the widespread problems concerning DSC in neonates.

\section{Conflict of Interest Statement}

Authors have nothing to disclose with regard to commercial support.

We thank Patrik Efferz and Dr h.c. Daniel Becker for their technical support.

\section{References}

1. Egan JR, Butler TL, Cole AD, Aharonyan A, Baines D, Street N, et al. Myocar dial ischemia is more important than the effects of cardiopulmonary bypass on myocardial water handling and postopertive dysfunction: a pediatric animal model. J Thorac Cardiovasc Surg. 2008;136:1265-73.

2. Johnson J, Jaegers J, Li S, O'Brian SM, Li JS, Jacobs JP, et al. Center variation and outcomes associated with delayed sternal closure following stage 1 palliation for left heart syndrome. J Thorac Cardiovasc Surg. 2010;139: 1205-10.

3. Tabbutt S, Duncan BW, McLaughlin D, Wessel DL, Jonas RA, Laussen PC. Delayed sternal closure after cardiac operations in a pediatric population. J Thorac Cardiovasc Surg. 1997;113:886-93.

4. Harder EE, Gaies MG, Yu S, Donohue JE, Hanauer DA, Goldberg CS, et al. Risk factors for surgical site infection in pediatric cardiac surgery patients undergoing delayed sternal closure. J Thorac Cardiovasc Surg. 2013;146: 326-33.

5. Samir K, Riberi A, Ghez O, Ali M, Metras D, Kreitmann B. Delayed sternal closure: a life-saving measure in neonatal open heart surgery; could it be predictable? Eur J Cardiothorac Surg. 2002;21:787-93. 
6. Petrich ES, Zumino AP. Electrophysiological responses to ischemia and reperfusion. In: Karmazyn M, ed. Myocardial Ischemia: Mechanism, Reperfusion, Protection. Basel: Birkhaeuser; 1996:115-33.

7. Julia PL, Kofsky ER, Buckberg GD, Young HH, Bugyi HI. Studies of myocardial protection in the immature heart. J Thorac Cardiovasc Surg. 1990;100:879-87.

8. Wittnich C, Su J, Boscarino C, Belanger M. Age-related differences in myocardial hydrogen ion buffering during ischemia. Mol Cell Biochem. 2006;285:61-7.

9. Ivorra $\mathrm{A}$, Genescà $\mathrm{M}$, Sola $\mathrm{A}$, Palacios L, Villa R, Hotter G, et al. Bioimpedance dispersion width as a parameter to monitor living tissues. Physiol Meas. 2005;26: 165-73.

10. Schaefer M, Gross W, Ackemann J, Gebhard MM. The complex dielectric spectrum of heart tissue during ischemia. Bioelectrochemistry. 2002;58:171-80.

11. Dhein S, ed. Cardiac Gap Junctions. Basel: Karger; 1998.

12. Gersing E, Kehrer G, Schaefer M. Characterization of organ tissue during the transition from life to death: impedance of the liver. Med Biol Eng Comput. 1999;37(suppl 2):98-9.

13. Da Luz VF, Otsuki DA, Gonzales MM, Negri EM, Cakdini EG, DamacenoRodriguez NR, et al. Myocardial protection induced by fentanyl in pigs exposed to high-dose adrenaline. Clin Exp Pharmacol Physiol. 2015;42:1098-107.

14. Murphy J. Temperature and humidity control in surgery rooms. ASHRAE. 2006; 48:H18-25.

15. Knapp J, Groos W, Gebhard MM, Schaefer M. Surface contact measurement of electrical cell uncoupling in the mouse heart during ischemia. Bioelectrochemistry. 2005;67:67-73.

16. Gersing E. Messungen der elektrischen Impedanz von Organen-Apparative Ausrüstung für Forschung und klinische Anwendung [Measurement of electrical impedance in organs-measuring equipment for research and clinical applications]. Biomedizinische Technik. 1991;36:6-11.

17. Mellert F, Winkler K, Schneider C, Dudykevych T, Welz A, Osypka M, et al. Detection of (reversible) myocardial ischemic injury by means of electrical bioimpedance. IEEE Trans Biomed Eng. 2011;58:1511-8.

18. Gersing E. Impedance spectroscopy of the heart during ischemia. In: Winter UJ, ed. Thoracic Impedance Measurements in Clinical Cardiology. Stuttgart, New York: Georg Thieme Verlag; 1994:222-8.

19. Wojcik S, Lambotte L. A comparison of electrical impedance, inulin and chloride distribution for the measurement of extracellular space in the liver. Arch Int Physiol Biochem. 1976;84:346-8.

20. Salonikidis P, Kirichenko SN, Tatjanenko LV, Schwarz W, Vasilets LA. Extracellular $\mathrm{pH}$ modulates kinetics of the $\mathrm{Na}^{+} / \mathrm{K}^{+}$-ATPase. Biochim Biophys Acta. 2000;1509:496-504.
21. Wittnich C, Quaglietta D, Tan L, Belanger MP. Sex differences in newborn myocardial metabolism and response to ischemia. Pediatr Res. 2011;70: $148-52$.

22. Qualietta D, Belanger MP, Wittnich C. Ventricle-specific metabolic differences in the newborn piglet myocardium in vivo and during arrested global ischemia. Pediatr Res. 2008;63:15-9.

23. Vanghan-Jones RD, Wu ML. $\mathrm{pH}$ dependence of intrinsic $\mathrm{H}^{+}$buffering power in the sheep cardiac Purkinje fibre. J Physiol. 1990;425:429-48.

24. Kettenmann H, Ransom BR, Schlue WR. Intracellular pH shifts capable of uncoupling cultured oligodendrocytes are seen only in low $\mathrm{HCO}_{3}{ }^{-}$solution. Glia. 1990;3:110-7.

25. Padan E, Venturi M, Gerchman Y, Dover N. $\mathrm{Na}^{+} / \mathrm{H}^{+}$antiporters. Biochim Biophys Acta. 2001;1505:144-57.

26. Askenasy N, Navon G. Volume-related activities of sodium ion transporters: multinuclear NMR studies of isolated rat hearts. Am J Physiol. 1996;271: H94-102.

27. Berger R, Garnier Y. Pathophysiology of perinatal brain damage. Brain Res Brain Rev. 1999;30:107-34.

28. Miura T, Ohnuma Y, Kuno A, Tanno M, Ichikawa Y, Nakamura Y, et al. Protective role of gap junctions in preconditioning against myocardial infarction. Am J Physiol Heart Circ Physiol. 2004;286:H214-21.

29. Cascio WE, Yang H, Johnson TA, Muller-Borer BJ, Lemasters JJ. Electrical properties and conduction in reperfused papillary muscle. Circ Res. 2001;89: 807-14.

30. Garcia-Dorado D, Inserte J, Ruiz-Meana DVM, González MA, Solares J, Juliá M, et al. Gap junction uncoupler heptanol prevents cell-to-cell progression of hypercontracture and limits necrosis during myocardial reperfusion. Circulation. 1997:96:3579-86.

31. Schaefer M, Gersing E, Gebhard MM. Characterization of organ tissue during the transition between life and death: cardiac and skeletal muscle. Med Biol Eng Comput. 1999;37(suppl 2):100-1.

32. Kalogeris T, Baines CP, Krenz M, Korthuis RJ. Cell biology of ischemia/reperfusion injury. Int Rev Cell Mol Biol. 2012;298:229-317.

33. An MY, Canel EP, Jang IH, Revel D, Fossum TW, Chung NS, et al. Development and evaluation of a new apparatus for continuous perfusion of isolated perfused pig heart. J Vet Sci. 2002;3:219-32.

Key Words: gap junction uncoupling, ischemia, neonates 